\title{
EVALUATING CHANGES IN THE ELEMENTAL COMPOSITION OF MICROMETEORITES DURING ENTRY INTO THE EARTH'S ATMOSPHERE
}

\author{
N. G. Rudraswami ${ }^{1}$, M. Shyam Prasad ${ }^{1}$, S. Dey ${ }^{1,2}$, J. M. C. Plane ${ }^{3}$, W. Feng ${ }^{3}$, and S. Taylor ${ }^{4}$ \\ ${ }^{1}$ National Institute of Oceanography (Council of Scientific and Industrial Research), Dona Paula, Goa 403004, India; rudra@nio.org \\ 2 Indian Institute of Technology, Roorkee, Uttarakhand 247667, India \\ ${ }^{3}$ School of Chemistry, University of Leeds, Leeds LS2 9JT, UK \\ ${ }^{4}$ Cold Regions Research and Engineering Laboratory, 72 Lyme Road, Hanover, NH 03755-1290, USA \\ Received 2015 August 19; accepted 2015 October 17; published 2015 November 17
}

\begin{abstract}
We evaluate the heating of extraterrestrial particles entering the atmosphere using the comprehensive chemical ablation model (CABMOD). This model predicts the ablation rates of individual elements in a particle with a defined size, composition, entry velocity, and entry angle with respect to the zenith (ZA). In the present study, bulk chemical analyses of 1133 Antarctica micrometeorites (collected from the south pole water well) are interpreted using CABMOD. The marked spread in $\mathrm{Fe} / \mathrm{Si}$ values in unmelted, partially melted, and melted micrometeorites is explained by the loss of relatively volatile Fe during atmospheric entry. The combined theoretical modeling and elemental composition of the micrometeorites ( $\mathrm{Mg} / \mathrm{Si}$ ratios) suggest that $\sim 85 \%$ of particles have a provenance of carbonaceous chondrites, the remaining $\sim 15 \%$ are either ordinary or enstatite chondrites. About $65 \%$ of the micrometeorites have undergone $<20 \%$ ablation, while a further $20 \%$ have lost between $20 \%$ and $60 \%$ of their original mass. This has implications for understanding the micrometeorite flux that reaches the Earth's surface, as well as estimating the pre-atmospheric size of the particles. Our work shows that the unmelted particles that contribute $\sim 50 \%$ to the total micrometeorite collection on Earth's surface have a small entry zone: $\mathrm{ZA}=60^{\circ}-$ $90^{\circ}$ if the entry velocity is $\sim 11 \mathrm{~km} \mathrm{~s}^{-1}$, and $\mathrm{ZA}=80^{\circ}-90^{\circ}$ for $>11-21 \mathrm{~km} \mathrm{~s}^{-1}$.
\end{abstract}

Key words: atmospheric effects - Earth - interplanetary medium - meteorites, meteors, meteoroids - Sun: general

\section{INTRODUCTION}

The extraterrestrial dust entering the Earth's atmosphere $\left(\sim 30,000-40,000 \mathrm{t} \mathrm{yr}^{-1}\right)$ is produced from comets and asteroids, and is a unique source of information on the formation processes of the early solar system (Love \& Brownlee 1993; Peucker-Ehrenbrink \& Ravizza 2000; Plane 2012). The size of most of the dust ranges from a few $\mu \mathrm{m}$ to a few $\mathrm{mm}$. A significant aspect of micrometeorite studies is that some of these particles may have sampled unfamiliar asteroids that are not represented in our meteorite collection (Yada et al. 2005; Gounelle et al. 2009). The dust particles are anticipated to originate predominantly in the asteroid belt and drift further into the inner solar system with a large probability of getting trapped in orbital resonance with Earth due to their smaller orbital eccentricities compared to cometary particles (Dermott et al. 1994; Reach et al. 1997; Brownlee 2001, pp. 1-12). There is some noteworthy contribution from the cometary bodies based on Infrared Astronomical Satellite (IRAS) data, although the IRAS evidence is not very clear to allow us to arrive at accurate estimates (Dermott et al. 1994, 1996). Similarly, cosmic background explorer observations suggested trapping asteroidal dust dominantly, making cometary dust insignificant (Kortenkamp et al. 2001, pp. 13-30). The numerical model by Kortenkamp \& Dermott (1998) estimated that $\sim 25 \%$ of dust reaching Earth is contributed by comets. Nesvorný et al. (2010, 2011) suggested that comets from the Jupiter family are a major source of dust particles and contribute $>80 \%$ of dust flux arriving at the Earth, in contradiction to above estimates. In any circumstance, estimating the exact contribution of the asteroidal and cometary reservoirs to the total flux is challenging. The low orbital eccentricities of asteroidal dust compared to those of higher eccentricities of cometary dust gives an advantage of greater gravitational capture cross section to asteroidal particles, making them the largest contributor of extraterrestrial dust, probably followed by cometary dust (Flynn 1989b; Kortenkamp \& Dermott 1998). The cometary particles traveling at higher velocities encounter a small amount gravitational capture than their counterpart asteroidal particles (Flynn 1989b; Brownlee 2001). However, it is worthwhile to note that the cometary particles trapped in resonance with Jupiter will have similar behavior to that of asteroid dust particles (Kortenkamp et al. 2001, pp. 13-30).

The bulk chemical composition of a meteoroid can change because of the rapid heating it experiences during atmospheric entry. Besides a relatively small loss of matter through sputtering with air molecules, the particle's temperature may reach its melting point and then lose a much larger fraction of mass through evaporation. Both of these processes are described by the term "ablation" (Vondrak et al. 2008). The degree of elemental change depends on the range of the heating event it undergoes, which in turn depends on the density, mass, chemical composition, entry velocity, and entry zenith angle (ZA) of the particle. Understanding the nature and extent of the changes in physical and chemical properties may provide insights into the source of the particle. For many decades, studies of the chemical composition did not make a quantitative correction for ablation in order to infer the original composition of the particle. Indeed, although the effects of heating due to variations in size, ZA, and entry velocity were discussed (e.g., Fraundorf 1980; Flynn 1989a; Love \& Brownlee 1991), the problem of understanding changes in the chemical composition during entry has not been a subject of extensive investigation.

The purpose of this work is to understand the changes in chemical composition during atmospheric heating by using the Chemical Ablation Model (CABMOD) developed by Vondrak et al. (2008). In particular, we will focus on changes to 
elemental ratios as a function of entry parameters. The chemical and mineralogical compositions of 1133 Antarctic micrometeorites will then be examined in order to infer the degree of mass loss and compositional alteration experienced during atmospheric entry, and hence the nature of the particles pre-entry.

\section{SAMPLE COLLECTIONS}

The samples were collected in 2000 from the South Pole Water Well (SPWW) at a depth of $\sim 100 \mathrm{~m}$ below the snow surface. This melt water well had a diameter of $\sim 24 \mathrm{~m}$, a depth of $\sim 15 \mathrm{~m}$, and a water volume of $\sim 5000 \mathrm{~m}^{3}$ (Taylor et al. 1998, 2000). The micrometeorites collected from this well were dated to between 1100 and 1500 AD (Taylor et al. 1998). The polar ice offers a pristine environment for micrometeorite collection where the melt water is filtered and the filtrates are examined for micrometeorites. Contaminants are very few in this environment and the compressed ice also provides a preconcentration of the extraterrestrial particles from the large volumes of ice melted. The polar samples are better preserved and therefore less weathered compared to deep sea micrometeorite collections. The samples collected in different size ranges above $50 \mu \mathrm{m}$ were sieved into various size fractions (Taylor et al. 1998). Using a binocular microscope, 1200 particles were sorted, mounted in epoxy, and polished for further study using a scanning electron microscope and electron microprobe. There are standard parameters for the identification of extraterrestrial particulate matter identified over a period of time (Blanchard et al. 1980; Brownlee et al. 1997; Taylor et al. 2000 and Genge et al. 2008): spherical morphology or even non-spherical and irregular shapes for unmelted particles, the presence of magnetite rims due to entry heating, $\mathrm{Fe}-\mathrm{Ni}$ bead, platinum group nuggets, $\mathrm{Mg}$-rich relict olivines, the formation of vesicles, chemical composition, elemental ratios, mineralogical properties, and the absence of terrestrially abundant elements. The classification of the micrometeorites is based on the textures and mineralogical composition as suggested in Genge et al. (2008).

\section{ANALYTICAL TECHNIQUES}

Back-scattered electron (BSE) images of the polished epoxymounted and carbon-coated micrometeorites were obtained using a JEOL JSM 5800LV SEM with an OXFORD INCA Energy Dispersive Spectrometer detector (EDS, ISIS-300 at the National Institute of Oceanography, Goa). The image is useful for classifying and identifying the proper phases for chemical analyses using a Cameca SX5 Electron Micro Probe Analyzer (at the National Institute of Oceanography, Goa) equipped with four spectrometers. The elemental compositions determined in the micrometeorites were $\mathrm{Na}, \mathrm{Mg}, \mathrm{Si}, \mathrm{Al}, \mathrm{P}, \mathrm{K}, \mathrm{Ca}, \mathrm{Ti}, \mathrm{Cr}, \mathrm{Mn}$, $\mathrm{Fe}$, and $\mathrm{Ni}$. The operating conditions used were as follows: accelerating voltage: $\sim 15 \mathrm{kV}$, beam current $\sim 12 \mathrm{nA}$, and beam diameter of $\sim 1-2 \mu \mathrm{m}$. The data are corrected using the PAP model (Pouchou \& Pichoir 1991, pp. 31-75). The analytical totals are less than $100 \%$ in some micrometeorites, which can be due to multiple reasons. The presence of the hydrous phases or porous contents, sub-micron void spaces, and cracks result in analytical deficiencies. However, care is taken by carrying out multiple analyses on the same spot. In any case, a small deviation from $100 \%$ can be considered to be within the permissible limits of the instrument analytical capabilities.

\section{ABLATION MODEL DESCRIPTION}

CABMOD (Vondrak et al. 2008) uses the classical physics equations to describe the time dependence of the meteoroid energy and velocity. The model includes sputtering by collision with air molecules before the particle melts, followed by Langmuir evaporative loss of metal atoms and oxides from the molten particles (treated by the thermodynamic model MAGMA) as a function of altitude (Schaefer \& Fegley 2005). Particles are considered to be a single phase with a density of $2 \mathrm{~g} \mathrm{~cm}^{-3}$, with a CI composition taken from multiple sources (Mason 1971; Sears \& Dodd 1988, pp. 3-31; Lodders \& Fegley 1998). The fact that the fundamental properties of density for the majority of unmelted extraterrestrial particles have been suggested to be $2 \mathrm{~g} \mathrm{~cm}^{-3}$, which is similar to that of the CI chondrites, suggests that the particle are primitive (Love et al. 1994). In addition, the major element compositions of the micrometeorites studied by various groups are close to CI composition (e.g., Brownlee et al. 1997; Taylor et al. 2000; Prasad et al. 2013). Therefore, the CI chondrites with a density of $2 \mathrm{~g} \mathrm{~cm}^{-3}$ is an appropriate choice for the model calculation based on observations on the large population of micrometeorites by many investigators.

In the present study, we use CABMOD to quantify the elemental composition changes that particles undergo as a function of particle diameter, velocity, and ZA. Differing combinations of these variables can produce similar compositional changes. For those particles with a size range from 100 to few hundred $\mu \mathrm{m}$, the maximum entry velocity for a majority of the particles to survive atmospheric entry is $\sim 16 \mathrm{~km} \mathrm{~s}^{-1}$. The choice of this size is based on the population of the micrometeorites studied (e.g., Taylor et al. 2000; Prasad et al. 2013). If the velocity of the particle goes beyond $16 \mathrm{~km} \mathrm{~s}^{-1}$, the ablation can surpass $\sim 70 \%$ (Table 1 ). However, for particles less than $100 \mu \mathrm{m}$ in size, there is greater chance of survival even at higher velocities. For the present study, we have used the following boundary conditions: entry velocity of $\leqslant 16 \mathrm{~km} \mathrm{~s}^{-1}$, peak temperature the particle can attain during entry to $<2000 \mathrm{~K}$, sizes ranging from $\sim 100 \mu \mathrm{m}$ to few hundred $\mu \mathrm{m}$ across, and ZAs of $\sim 45^{\circ}-90^{\circ}$. Love \& Brownlee (1991) suggested that the increase in mass loss with increasing temperature reaches a zenith at $2000 \mathrm{~K}$, which is suggested as the practical upper limit that any particle can reach during atmospheric entry. Even if a particle survives beyond this temperature, its chemical composition deviates due to largescale vaporization and tends to lose its characteristic features such as elemental ratios that are crucial for the identification of precursors. Most of the micrometeorites recovered have sizes in the range of 100 to few hundred $\mu \mathrm{m}$. However, model calculation suggests that $\mathrm{ZA} \sim 0^{\circ}-45^{\circ}$ will experience large heating and ablation depending on the velocity (discussed in Section 6.1 and Table 1). Hence, we restrict ourselves to velocities $\leqslant 16 \mathrm{~km} \mathrm{~s}^{-1}$ and temperatures $<2000 \mathrm{~K}$, as temperatures above this will lead to elemental vaporization that can potentially alter the chemical composition, losing our understanding on the precursors composition (Table 1). It should be noted that the present work does not consider the atmospheric fragmentation of a particle during entry (Lal \& Jull 2002).

\section{MICROMETEORITE CHEMICAL COMPOSITION}

We have classified 1133 Antarctica micrometeorites using BSE images. Although the mount was dominated by melted 
Table 1

The Percent of Mass Ablated for Various Sizes, Zenith Angles, and Entry Velocities

\begin{tabular}{|c|c|c|c|c|c|c|c|c|c|c|c|}
\hline \multirow[t]{2}{*}{ Entry Velocity $\left(\mathrm{km} \mathrm{s}^{-1}\right)$} & \multicolumn{11}{|c|}{ Percent of Mass Ablated } \\
\hline & Size $(\mu \mathrm{m})$ & $\mathrm{ZA}=0^{\circ}$ & $10^{\circ}$ & $20^{\circ}$ & $30^{\circ}$ & $40^{\circ}$ & $50^{\circ}$ & $60^{\circ}$ & $70^{\circ}$ & $80^{\circ}$ & $90^{\circ}$ \\
\hline \multirow[t]{4}{*}{11} & 100 & 1 & 1 & 0 & 0 & 0 & 0 & 0 & 0 & 0 & $\overline{0}$ \\
\hline & 200 & 3 & 3 & 3 & 2 & 2 & 1 & 1 & 0 & 0 & 0 \\
\hline & 300 & 16 & 15 & 13 & 10 & 7 & 4 & 2 & 0 & 0 & 0 \\
\hline & 400 & 33 & 32 & 29 & 25 & 18 & 11 & 5 & 0 & 0 & 0 \\
\hline \multirow[t]{4}{*}{16} & 100 & 22 & 21 & 18 & 14 & 9 & 5 & 2 & 1 & 0 & 0 \\
\hline & 200 & 76 & 75 & 72 & 67 & 59 & 45 & 26 & 8 & 0 & 0 \\
\hline & 300 & 93 & 93 & 92 & 89 & 85 & 77 & 62 & 35 & 0 & 0 \\
\hline & 400 & 96 & 95 & 95 & 95 & 94 & 90 & 80 & 58 & 0 & 0 \\
\hline \multirow[t]{4}{*}{21} & 100 & 90 & 89 & 87 & 83 & 76 & 64 & 43 & 14 & 0 & 0 \\
\hline & 200 & 97 & 97 & 97 & 96 & 96 & 95 & 91 & 71 & 0 & 0 \\
\hline & 300 & 97 & 97 & 97 & 97 & 97 & 97 & 96 & 93 & 0 & 0 \\
\hline & 400 & 98 & 98 & 98 & 97 & 97 & 97 & 97 & 96 & 0 & 0 \\
\hline \multirow[t]{4}{*}{26} & 100 & 97 & 97 & 97 & 97 & 96 & 95 & 92 & 72 & 16 & 0 \\
\hline & 200 & 97 & 97 & 97 & 97 & 97 & 98 & 97 & 96 & 77 & 0 \\
\hline & 300 & 98 & 98 & 98 & 98 & 98 & 97 & 97 & 97 & 95 & 0 \\
\hline & 400 & 98 & 98 & 98 & 98 & 98 & 98 & 97 & 97 & 96 & 0 \\
\hline \multirow[t]{4}{*}{31} & 100 & 98 & 98 & 98 & 99 & 98 & 98 & 97 & 95 & 65 & 0 \\
\hline & 200 & 98 & 98 & 98 & 98 & 98 & 97 & 97 & 98 & 96 & 0 \\
\hline & 300 & 98 & 98 & 98 & 98 & 98 & 98 & 98 & 97 & 97 & 0 \\
\hline & 400 & 98 & 98 & 98 & 98 & 98 & 98 & 98 & 98 & 98 & 0 \\
\hline
\end{tabular}
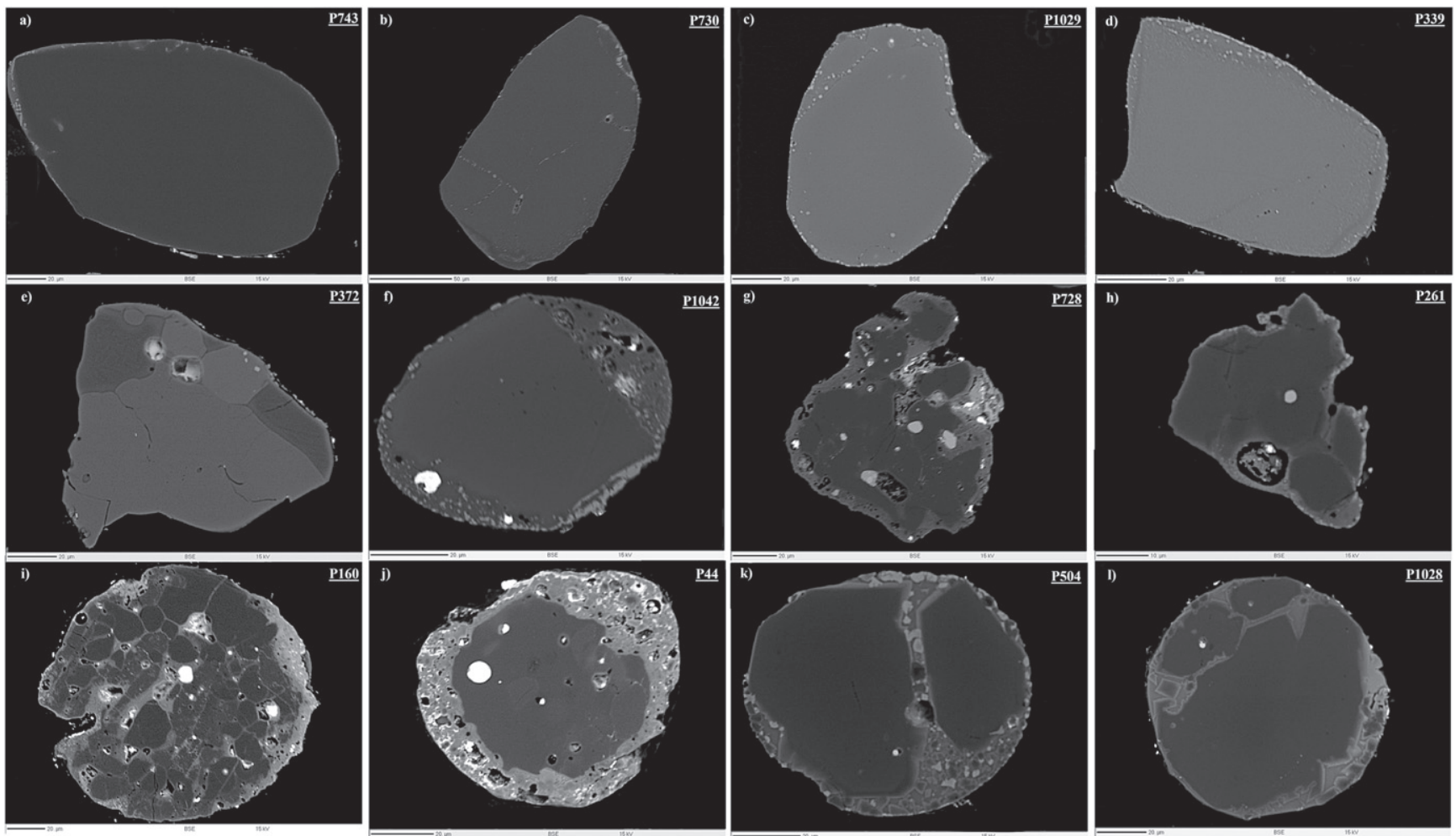

Figure 1. Back-scattered electron images of representative unmelted and relict-bearing micrometeorites collected from South Pole Water Well (SPWW). P743, P730, P1029, and P339 are unmelted single mineral micrometeorites. The single mineral micrometeorite P1029 has also been reported earlier by Taylor et al. (2012). P372 is a multiple mineral particle with a large portion dominated by pyroxene and some olivine; the dark gray region is Al-rich feldspathic glass. P728, P261, P160, and P44 have mixtures of olivine and pyroxene. P1042 exhibits a large relict grain. P504 and P1028 exhibit large multiple relict minerals. The bulk chemical compositions of the unmelted and relict-bearing micrometeorites are listed in Table 2. 
Table 2

Bulk Chemical Composition (wt\%) of Unmelted and Relict-bearing Micrometeorites

\begin{tabular}{|c|c|c|c|c|c|c|c|c|c|c|c|}
\hline Micrometeorites & $\mathrm{Na}_{2} \mathrm{O}$ & $\mathrm{MgO}$ & $\mathrm{Al}_{2} \mathrm{O}_{3}$ & $\mathrm{SiO}_{2}$ & $\mathrm{CaO}$ & $\mathrm{Cr}_{2} \mathrm{O}_{3}$ & $\mathrm{MnO}$ & $\mathrm{FeO}$ & $\mathrm{CoO}$ & $\mathrm{NiO}$ & Total \\
\hline \multicolumn{12}{|l|}{ (a) Unmelted } \\
\hline P339 & $\ldots$ & 34.9 & $\ldots$ & 37.6 & 0.2 & 0.3 & 0.7 & 24.1 & $\ldots$ & $\ldots$ & 97.8 \\
\hline P46 & 0.1 & 33.8 & 1.1 & 39.1 & 0.7 & 0.3 & 0.4 & 23.9 & $\ldots$ & 0.3 & 99.7 \\
\hline P561 & 0.8 & 30.9 & 1.5 & 47.4 & 1.2 & 0.5 & 0.7 & 12.9 & $\ldots$ & $\ldots$ & 96.3 \\
\hline $\mathrm{P} 730$ & $\ldots$ & 41.7 & $\ldots$ & 38.8 & $\ldots$ & $\ldots$ & 0.4 & 18.2 & $\ldots$ & $\ldots$ & 99.2 \\
\hline P743 & $\ldots$ & 53.7 & 0.1 & 41.7 & 0.2 & 0.3 & 0.1 & 2.3 & $\ldots$ & $\ldots$ & 98.6 \\
\hline P1029 & 0.1 & 30.3 & 0.7 & 37.2 & 0.7 & 0.3 & 0.4 & 28.3 & $\ldots$ & 0.1 & 98.0 \\
\hline P1042 & $\ldots$ & 26.5 & 0.4 & 34.5 & 0.5 & 0.3 & 0.3 & 34.1 & 0.1 & 0.4 & 97.1 \\
\hline P29 & 0.8 & 26.2 & 5.7 & 45.7 & 3.7 & 0.5 & 0.8 & 14.7 & $\ldots$ & 0.1 & 98.3 \\
\hline P261 & $\ldots$ & 43.3 & 2.4 & 46.8 & 1.7 & 0.5 & 0.1 & 3.7 & $\ldots$ & 0.2 & 98.8 \\
\hline P372 & 1.5 & 25.0 & 4.5 & 52.8 & 0.9 & 0.1 & 0.3 & 9.7 & $\ldots$ & $\ldots$ & 95.2 \\
\hline P727 & 0.1 & 29.6 & 0.2 & 36.0 & 0.4 & 0.2 & 0.5 & 32.1 & $\ldots$ & 0.1 & 99.1 \\
\hline \multicolumn{12}{|l|}{ (b) Relict-bearing } \\
\hline P44 & $\ldots$ & 32.9 & 1.5 & 44.0 & 1.0 & 0.5 & 0.2 & 18.3 & $\ldots$ & 0.1 & 98.6 \\
\hline P59 & $\ldots$ & 34.1 & 1.3 & 36.8 & 1.7 & 0.3 & 0.2 & 23.6 & $\ldots$ & 0.6 & 98.6 \\
\hline P88 & $\ldots$ & 39.4 & 1.3 & 45.0 & 0.5 & 0.4 & 0.2 & 11.2 & $\ldots$ & 0.4 & 98.4 \\
\hline P95 & 0.2 & 26.7 & 1.3 & 36.8 & 1.5 & 0.4 & 0.3 & 28.0 & $\ldots$ & 0.2 & 95.4 \\
\hline P106 & 0.1 & 23.0 & 0.6 & 52.1 & 0.7 & 0.5 & 0.6 & 19.7 & $\ldots$ & 0.1 & 97.5 \\
\hline P108 & 0.1 & 27.7 & 1.6 & 43.6 & 1.2 & 0.5 & 0.4 & 19.6 & $\ldots$ & 1.2 & 96.0 \\
\hline P109 & 0.1 & 27.0 & 1.2 & 40.5 & 1.6 & 0.7 & 0.2 & 23.0 & $\ldots$ & 0.6 & 95.0 \\
\hline P128 & 0.9 & 27.9 & 4.0 & 55.1 & 2.2 & 0.6 & 0.4 & 6.7 & $\ldots$ & 0.1 & 98.1 \\
\hline P160 & 0.3 & 37.2 & 2.8 & 44.4 & 1.6 & 0.7 & 0.2 & 9.4 & $\ldots$ & 0.3 & 96.8 \\
\hline P167 & $\ldots$ & 29.6 & 1.2 & 41.2 & 1.1 & 0.6 & 0.5 & 23.5 & $\ldots$ & 0.1 & 97.9 \\
\hline P220 & 0.5 & 22.8 & 3.6 & 42.9 & 3.6 & 0.3 & 0.3 & 23.4 & $\ldots$ & 0.2 & 97.7 \\
\hline P251 & 1.0 & 27.8 & 2.0 & 57.7 & 1.4 & 0.5 & 0.4 & 6.9 & $\ldots$ & $\ldots$ & 98.0 \\
\hline P302 & $\ldots$ & 30.3 & 1.3 & 44.4 & 1.2 & 0.5 & 0.5 & 18.3 & $\ldots$ & 0.1 & 96.8 \\
\hline P304 & 0.3 & 25.3 & 1.6 & 37.1 & 1.5 & 0.6 & 0.4 & 29.4 & $\ldots$ & 0.1 & 96.4 \\
\hline P351 & $\ldots$ & 33.4 & 0.8 & 37.7 & 0.7 & 0.3 & 0.3 & 24.4 & $\ldots$ & $\ldots$ & 97.7 \\
\hline P363 & 0.2 & 31.1 & 2.1 & 46.4 & 1.7 & 0.4 & 0.2 & 13.4 & $\ldots$ & 0.5 & 96.0 \\
\hline P392 & $\ldots$ & 55.4 & 0.1 & 40.1 & 0.4 & 0.2 & 0.1 & 0.9 & $\ldots$ & $\ldots$ & 97.4 \\
\hline P408 & $\ldots$ & 26.2 & 3.5 & 35.0 & 4.0 & 0.3 & 0.2 & 27.1 & 0.1 & 0.1 & 96.5 \\
\hline P415 & 0.1 & 23.8 & 3.8 & 43.9 & 3.8 & 0.4 & 0.6 & 20.3 & $\ldots$ & 0.1 & 96.8 \\
\hline P419 & 0.1 & 28.9 & 3.7 & 44.4 & 2.8 & 0.3 & 0.4 & 17.4 & $\ldots$ & 0.2 & 98.3 \\
\hline P504 & $\ldots$ & 34.3 & 0.6 & 36.7 & 0.7 & 0.4 & 0.7 & 24.9 & $\ldots$ & 0.1 & 98.4 \\
\hline P522 & $\ldots$ & 51.1 & 0.5 & 41.6 & 1.4 & 0.2 & 0.2 & 3.4 & $\ldots$ & 0.2 & 98.5 \\
\hline P541 & 0.2 & 30.4 & 1.7 & 39.4 & 1.4 & 0.2 & 0.5 & 22.7 & 0.1 & 0.3 & 96.9 \\
\hline P544 & $\ldots$ & 33.6 & 1.8 & 38.8 & 1.4 & 0.2 & 0.2 & 22.0 & $\ldots$ & 1.0 & 99.1 \\
\hline P586 & $\ldots$ & 24.9 & 1.4 & 49.8 & 1.1 & 0.5 & 0.4 & 18.7 & 0.1 & 0.5 & 97.4 \\
\hline P607 & $\ldots$ & 34.7 & 1.8 & 45.9 & 1.5 & 0.4 & 0.2 & 12.8 & $\ldots$ & 0.3 & 97.6 \\
\hline P627 & 0.1 & 30.9 & 1.7 & 49.1 & 3.2 & 0.4 & 0.2 & 11.0 & $\ldots$ & 0.5 & 97.2 \\
\hline P645 & 0.2 & 34.2 & 1.0 & 40.5 & 3.3 & 0.0 & 0.3 & 15.3 & $\ldots$ & 0.1 & 95.2 \\
\hline P668 & $\ldots$ & 27.2 & 2.3 & 38.3 & 2.3 & 0.4 & 0.2 & 26.8 & $\ldots$ & 0.4 & 98.0 \\
\hline P700 & 0.4 & 26.1 & 2.0 & 37.6 & 1.5 & 0.2 & 0.4 & 29.3 & $\ldots$ & 0.3 & 97.8 \\
\hline P703 & 0.5 & 27.1 & 1.7 & 36.6 & 1.3 & 0.3 & 0.4 & 30.0 & $\ldots$ & 0.1 & 98.1 \\
\hline P710 & $\ldots$ & 33.2 & 1.7 & 37.9 & 1.6 & 0.1 & 0.2 & 22.4 & $\ldots$ & 0.5 & 97.7 \\
\hline P721 & 0.4 & 29.9 & 2.1 & 43.6 & 2.0 & 0.3 & 0.5 & 19.7 & $\ldots$ & 0.1 & 98.7 \\
\hline P728 & $\ldots$ & 44.1 & 1.1 & 45.3 & 0.6 & 0.5 & 0.2 & 6.8 & $\ldots$ & 0.1 & 98.7 \\
\hline P791 & 1.9 & 22.1 & 2.1 & 43.6 & 1.6 & 0.2 & 0.6 & 25.4 & $\ldots$ & $\ldots$ & 97.7 \\
\hline P913 & 0.2 & 28.0 & 0.7 & 50.9 & 0.9 & 0.2 & 0.4 & 16.8 & $\ldots$ & $\ldots$ & 98.1 \\
\hline P930 & 0.1 & 31.9 & 0.4 & 38.0 & 0.6 & 0.2 & 0.3 & 28.0 & $\ldots$ & 0.1 & 99.6 \\
\hline P931 & $\ldots$ & 42.0 & 0.2 & 38.9 & 0.2 & 0.3 & 0.9 & 16.3 & $\ldots$ & 0.1 & 98.9 \\
\hline P939 & $\ldots$ & 43.3 & 1.8 & 46.1 & 1.2 & 0.5 & 0.3 & 4.5 & $\ldots$ & 0.2 & 98.1 \\
\hline P1028 & $\ldots$ & 30.4 & 1.5 & 37.1 & 1.4 & 0.3 & 0.5 & 24.4 & $\ldots$ & $\ldots$ & 95.7 \\
\hline P1162 & 0.5 & 32.9 & 1.4 & 49.2 & 1.0 & 0.3 & 0.3 & 10.2 & $\ldots$ & 0.9 & 96.7 \\
\hline P1209 & 0.2 & 24.3 & 3.3 & 38.2 & 2.8 & 0.3 & 0.3 & 27.4 & 0.1 & 0.2 & 97.2 \\
\hline
\end{tabular}

spherules, there were 11 particles that can be classified as unmelted micrometeorites. The remaining micrometeorites are classified as follows: 42 are relict-grain bearing, 57 are scoriaceous, 355 are porphyritic, 137 are barred, 119 are cryptocrystalline 371 are glass, 18 are I-type spherules, and 23 are G-type spherules. Among the porphyritic, a large number of spherules had relict grains with sizes $>50 \mu \mathrm{m}$, indicative of preservation during atmospheric entry. Olivine is the most abundant relict mineral, dominated by a fosteritic composition; however, some minor minerals such as pyroxene, spinel, and plagioclase are also found. Figure 1 shows representative BSE images of the unmelted and relict-bearing micrometeorites. Figures 1(a)-(d) are unmelted single mineral grains with uniform chemical composition. Figure 1(e) is an 

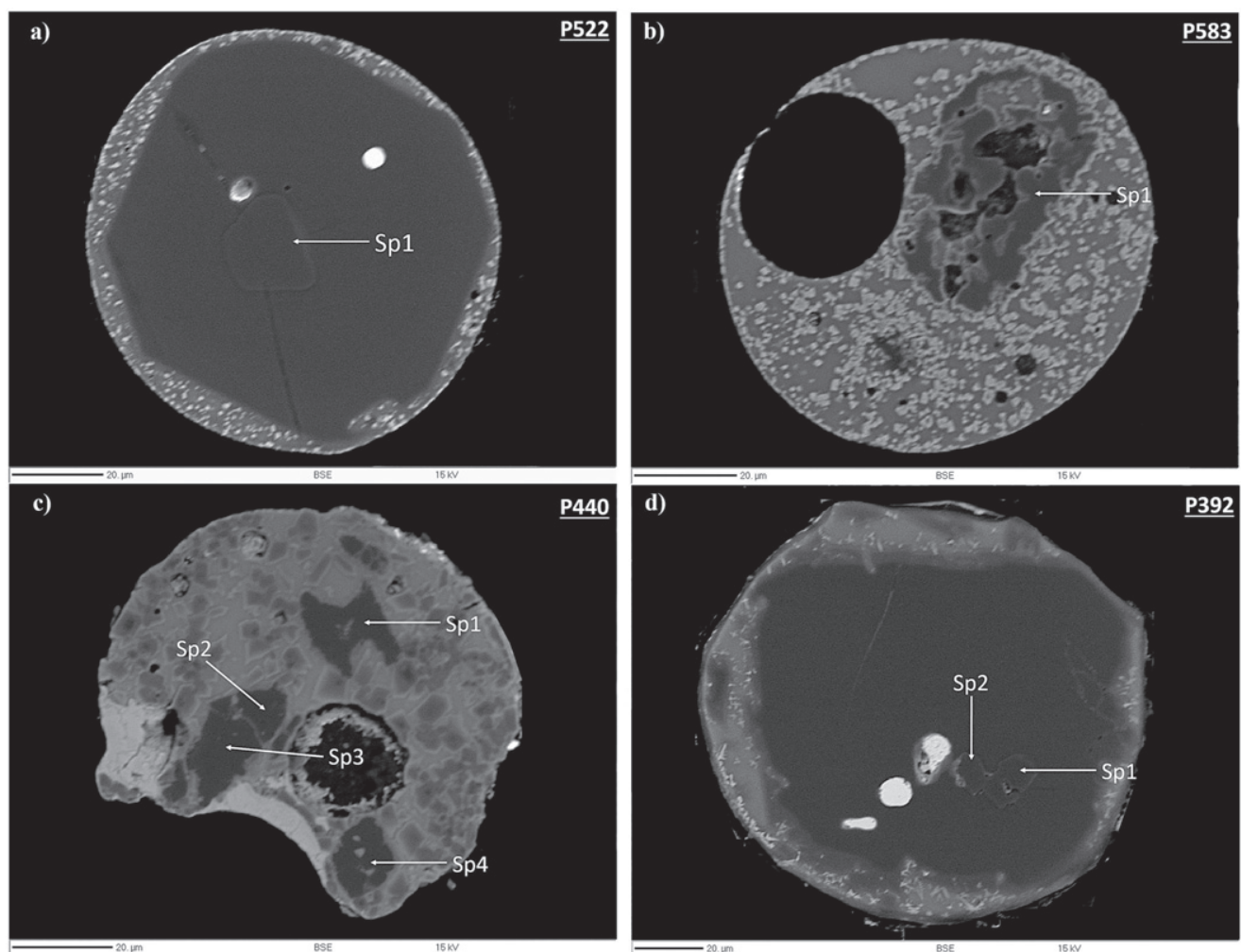

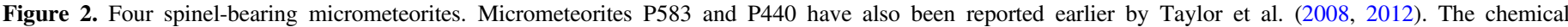
compositions of the spinel and the relict minerals of the micrometeorites are given in Table 3 .

Table 3

Chemical Composition (wt\%) of Spinel Found in Micrometeorites

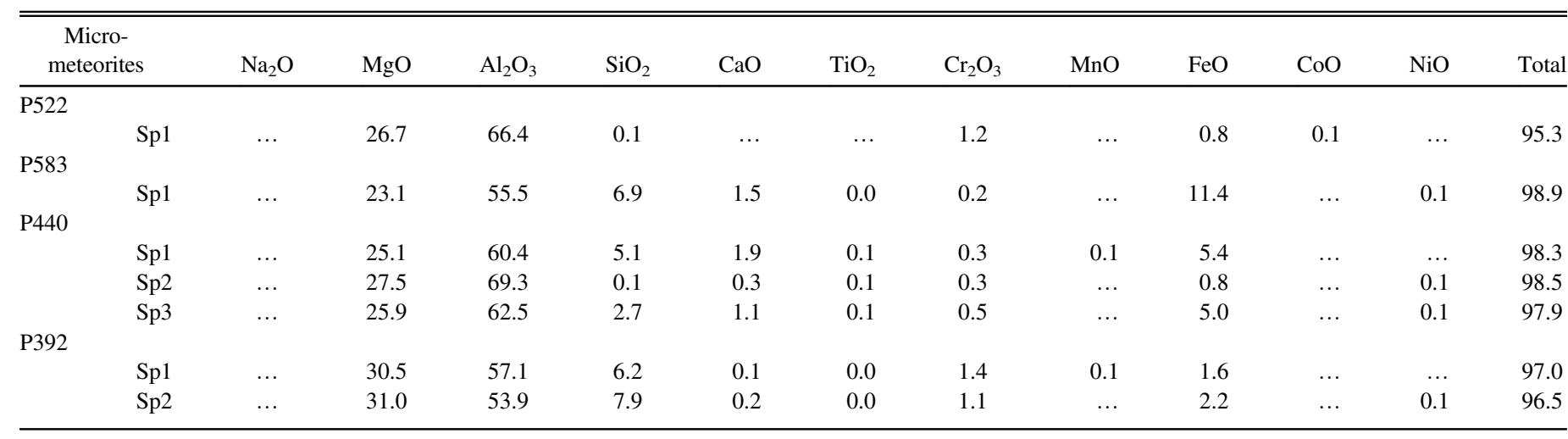

example of a multiple mineral micrometeorite. Figures 1(f)-(h) are micrometeorites that experienced partial heating during atmospheric entry, but largely preserved their relict mineral compositions. P160 shows the presence of a large number of Mg-rich fosterites along with pyroxenes (Figure 1(i)). Large relict-grain bearing micrometeorites are seen in Figures 1(j)-(l). Table 2 lists the bulk chemical composition for the unmelted and relict-bearing micrometeorites. The unmelted micrometeorites should preserve chemical compositions similar to those of their parent bodies. Spinel is one the refractory minerals that is rarely found in micrometeorites, though commonly found in calcium aluminum-rich inclusions (CAIs). Previously, some evidence of spinel earlier in micrometeorites/cosmic spherules has been reported (Taylor et al. 2008, 2012). In the present study, spinels were observed in four spherules, whose BSE images are shown in Figure 2 and chemical composition listed in Table 3.
Multiple analyses by electron microprobe on different phases and compositions are helpful in finding the bulk chemical composition of micrometeorites. The Lispix software program (http://www.nist.gov/lispix/) produces phase images where a modal proportion of the volume is calculated (Berlin 2009). This method to determine the bulk chemical composition is more accurate than a simple average of electron microprobe data, or the defocussed beam technique where the broad beam frequently hits a void space or vesicle, leading to low total counts of chemical composition. The bulk chemical compositions of the cosmic spherules are similar to those found in the deep sea sediments and polar regions (Brownlee et al. 1997; Taylor et al. 2000; Rudraswami et al. 2012, 2014, 2015; Prasad et al. 2013). The depletion of volatile elements such as $\mathrm{Na}$ and $\mathrm{S}$, followed by $\mathrm{Fe}$, is evident during atmospheric heating. A plot of $\mathrm{Ca} / \mathrm{Si}$ versus $\mathrm{Al} / \mathrm{Si}$ follows along the solar composition line (Figure 3). The glass, barred olivine, and 


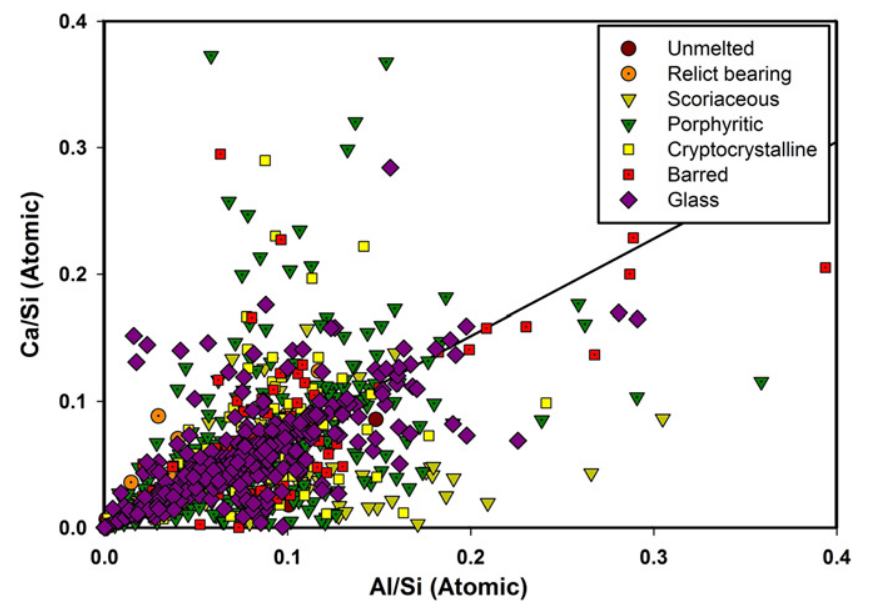

Figure 3. $\mathrm{Ca} / \mathrm{Si}$ vs. $\mathrm{Al} / \mathrm{Si}$ for different types of micrometeorites collected from the South Pole Water Well (SPWW). The solid line indicates the solar line.

cryptocrystalline spherules are essentially close to the solar line; however, there is some spread in other micrometeorites (e.g., scoriaceous and porphyritic). The $\mathrm{Mg} / \mathrm{Si}$ ratios exhibit a spread from 0.5-1.5 (Figure 4(a)), although dominated by the CI composition ratio irrespective of the type of micrometeorite. The same behavior of $\mathrm{Mg} / \mathrm{Si}$ is also seen in the case of the deep sea spherules (Brownlee et al. 1997; Prasad et al. 2013). Fe is more volatile than $\mathrm{Mg}$ (which is bound in the melt as a stable oxide), and its faster evaporation causes a much greater spread in the $\mathrm{Fe} / \mathrm{Si}$ ratio (Figure 4(b)), in contrast to $\mathrm{Mg} / \mathrm{Si}$. The $\mathrm{Fe} / \mathrm{Si}$ is spread much lower than the $\mathrm{CI}$ value. The peak at $\mathrm{Fe} / \mathrm{Si}>2$ is due to the Fe-rich composition in Scoriaceous, porphyritic, cryptocrystalline, and barred micrometeorites. The behavior of $\mathrm{Fe} / \mathrm{Si}$ is slightly different in the deep sea spherules, likely because of a magnetic bias in the collection that causes the collected spherules to be richer in Fe (Brownlee et al. 1997).

The $\mathrm{Al} / \mathrm{Si}$ (Figure 4(c)) and $\mathrm{Ca} / \mathrm{Si}$ (Figure 4(d)) ratios are in good agreement with their CI values, unlike $\mathrm{Fe} / \mathrm{Si}$. Si is more volatile than $\mathrm{Ca}$ and $\mathrm{Al}$, leading to the depletion of $\mathrm{Si}$ during entry (Hashimoto 1983; Vondrak et al. 2008) and a second peak of $\mathrm{Al} / \mathrm{Si}$ and $\mathrm{Ca} / \mathrm{Si}$. The $\mathrm{Mg}-\mathrm{Fe}-\mathrm{Si}$ ternary diagram (Figure 5) for 1110 micrometeorites (excluding G-type) along with the trend of extraterrestrial particles and terrestrial particles suggests that different types of collections from the deep sea, Antarctica, or Greenland have similar chemical composition ranges (Brownlee et al. 1997; Taylor et al. 2000; Rochette et al. 2008).

\section{DISCUSSION}

\subsection{Chemical Variation of Particles during Atmospheric Entry}

The present study focuses on understanding the changes in the elemental composition of the incoming particles as a function of size, ZA, and velocity. Here we examine the major elements such as $\mathrm{Si}, \mathrm{Mg}, \mathrm{Fe}, \mathrm{Ca}$, and $\mathrm{Al}$ which contribute more than $90 \%$ of the particle mass (along with O). For the present, the parameters considered will be discussed in Section 6.3. For example, considering the above constraints, for the minimum entry velocity of $\sim 11 \mathrm{~km} \mathrm{~s}^{-1}$, ZA $\sim 0^{\circ}$, and particle size $\sim 100 \mu \mathrm{m}$, the peak temperature achieved is $\sim 1700 \mathrm{~K}$ where the percent of ablation is close to $\sim 1 \%$. This percent of mass ablation and the peak temperatures achieved by the particles increases rapidly, primarily with entry velocity and ZA, but also as a function of the mass of the incoming particle. For two ZAs of $45^{\circ}$ and $60^{\circ}$ with different velocities and sizes, it can be seen in Figure 6 that the peak temperature of the particles exceeds $2000 \mathrm{~K}$ even for $200 \mu \mathrm{m}$ particles at velocities greater than $16 \mathrm{~km} \mathrm{~s}^{-1}$. The particles that have crossed $2000 \mathrm{~K}$ have greater chances to undergo large-scale changes in chemical composition by vaporization of elements, thereby losing distinctive features of the precursors (Love \& Brownlee 1991).

At an entry velocity of $11 \mathrm{~km} \mathrm{~s}^{-1}$, a large mass of the particles is preserved irrespective of ZA with maximum $\sim 30 \%$ ablation (Table 1). However, as the entry velocity increases, ablation increases for all ZA apart from near-horizontal entry where $\mathrm{ZA}=80^{\circ}-90^{\circ}$ (Figure 7 and Table 1 ). The survival chances of the particles without any disturbance are highest for those that enter in the narrow window of $\mathrm{ZA}=80^{\circ}-90^{\circ}$ and entry velocity $<21 \mathrm{~km} \mathrm{~s}^{-1}$. This is true for ZA $60^{\circ}-90^{\circ}$ and an entry velocity $11 \mathrm{~km} \mathrm{~s}^{-1}$ (Figure 6 and Table 1). Almost 50\% of the micrometeorites collected from the Greenland ice cap are unmelted, especially those in the size range of $50-10 \phi \mu \mathrm{m}$ (Maurette et al. 1987). Yada et al. (2004) found that nearly $60 \%$ of the particles collected around the Yamato Mountains in Antarctica are unmelted, while the remaining are cosmic spherules. The SPWW micrometeorite collection also found that roughly half of the particles collected were unmelted in the size range of $50-10 \phi \mu \mathrm{m}$ (Taylor et al. 2007b). The Antarctic and Greenland Ice collections therefore suggest that unmelted micrometeorites and melted spherules are approximately equal in number, unlike deep sea spherules (Taylor \& Brownlee 1991; Brownlee et al. 1997; Rudraswami et al. 2012; Prasad et al. 2013). There is a narrow zone of ZA and velocity that will allow a meteoroid with a diameter greater than $100 \mu \mathrm{m}$ to enter the atmosphere without melting and altering the mineralogical features or texture: $\mathrm{ZA}=80^{\circ}-90^{\circ}$ and entry velocity $<21 \mathrm{~km} \mathrm{~s}^{-1}$. The ZA $80^{\circ}-90^{\circ}$ is the zone where nearly $50 \%$ of the total recovered particles with sizes greater than $100 \mu \mathrm{m}$ reaches the Earth's surface survive ablation and are well preserved. However, if the velocity of the entering particle is $\sim 11 \mathrm{~km} \mathrm{~s}^{-1}$, then $\mathrm{ZA} 60^{\circ}-90^{\circ}$ is the minimum ablation zone for any size less than few hundred microns across as sputtering will always also occur in unmelted particles.

The elemental changes that the particles undergo are observed largely in $\mathrm{Mg}, \mathrm{Fe}$, and $\mathrm{Si}$, which contribute more than $90 \%$ of the particle mass in the oxide form as the major silicate minerals, followed by the refractory elements $\mathrm{Ca}$ and Al. Fe is the most volatile of these elements (after $\mathrm{Na}$ and $\mathrm{K}$ ) and after particle melting contributes most to the ablative loss, followed by $\mathrm{Si}$ and $\mathrm{Mg}$, while there is no major ablation of $\mathrm{Ca}$ and $\mathrm{Al}$ (Figure 8). For example, for a $\mathrm{ZA}=45^{\circ}$, diameter $\sim 200 \mu \mathrm{m}$, and entry velocity $\sim 16 \mathrm{~km} \mathrm{~s}^{-1}$, Fe decreases from $28 \mathrm{wt} \%$ to $<8 \mathrm{wt} \%$ by the time at the particle descends to $70 \mathrm{~km}$ altitude, while the loss in Fe results in the enrichment of $\mathrm{Mg}$ and $\mathrm{Si}$ from $\sim 15 \%$ and $16 \%$ to $25 \%$ and $19 \%$, respectively (Figure 9). The jogs in Figure 9 are the regions where the ablation begins to occur at the altitude of $95-101 \mathrm{~km}$. The first element to be ablated is $\mathrm{Na}$ followed by $\mathrm{K}$. As a result, the particle loses mass, but not of $\mathrm{Mg}, \mathrm{Si}$, or $\mathrm{Fe}$, so there seems to be a slight enrichment of these elements compared to their initial composition. For any given size, a smaller ZA and larger 


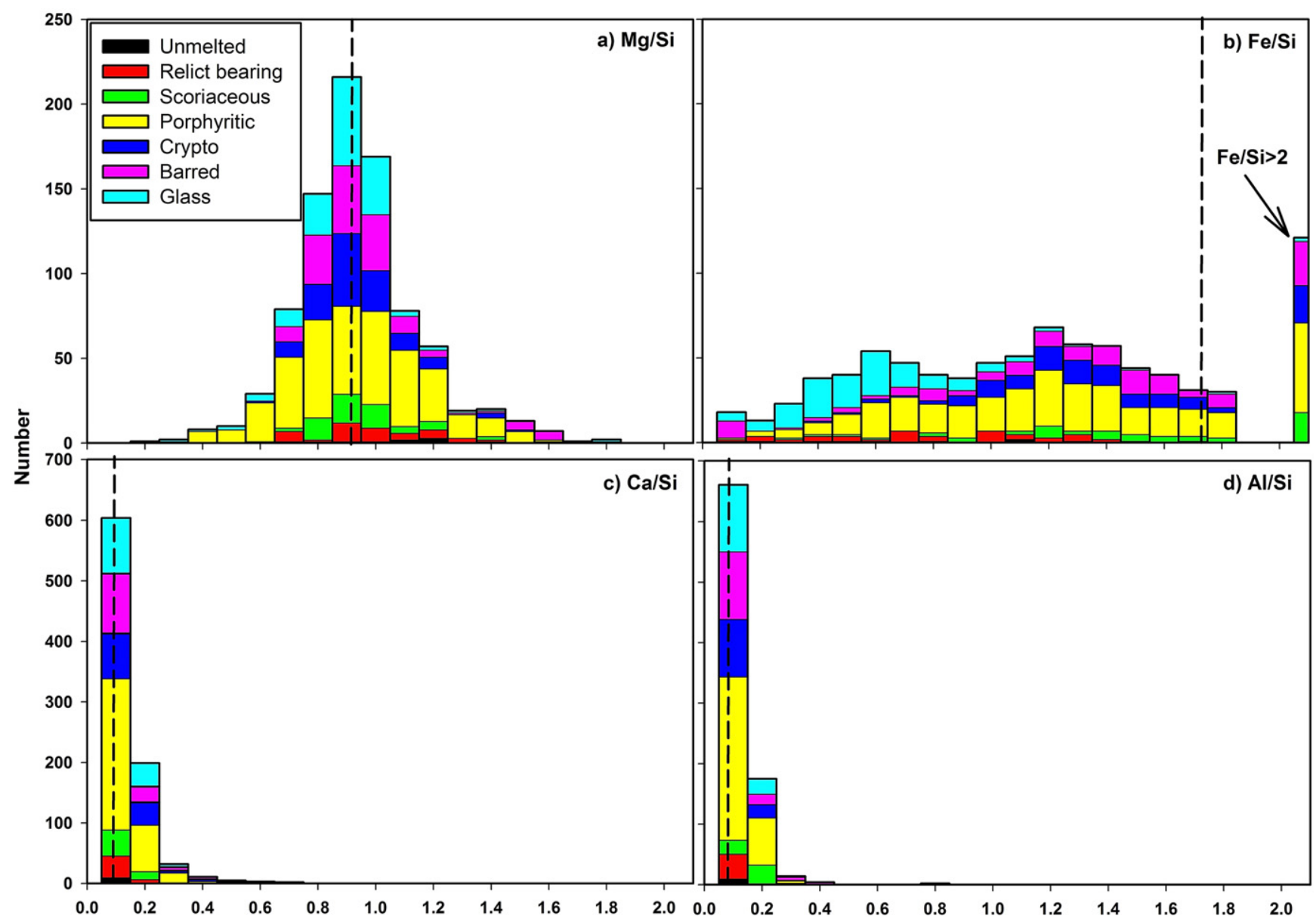

Figure 4. Histogram plot of the elemental ratio for different types of micrometeorites collected from the South Pole Water Well (SPWW): (a) $\mathrm{Mg} / \mathrm{Si}$, (b) Fe/Si, (c) $\mathrm{Ca} / \mathrm{Si}$, and (d) $\mathrm{Al} / \mathrm{Si}$. The dashed vertical line is the CI composition (Lodders \& Fegley 1998). The peaks of $\mathrm{Mg} / \mathrm{Si}, \mathrm{Ca} / \mathrm{Si}$, and Al/Si are similar to the CI composition, besides $\mathrm{Fe} / \mathrm{Si}$ which exhibits a large spread.

velocity give rise to a greater fraction of mass loss through elemental ablation (Table 1). As the ablative fraction increases, the $\mathrm{Fe} / \mathrm{Si}$ ratio decreases: $20 \%$ ablation results in a $33 \%$ decrease of the $\mathrm{Fe} / \mathrm{Si}$ ratio, and once ablation is higher than $70 \%$ the particle has lost more than $90 \%$ of its $\mathrm{Fe}$ (Figure 10(b)). The $\mathrm{Mg} / \mathrm{Si}$ ratios (Figure 10(a)) exhibit a reverse trend compared to $\mathrm{Fe} / \mathrm{Si}$. The $\mathrm{Mg} / \mathrm{Si}$ ratios increase with mass ablation until $80 \%$ of the mass is gone, at which point the ratio decreases. There is little change in the $\mathrm{Mg} / \mathrm{Si}$ ratio up to $\sim 20 \%$ ablation. A higher degree of ablation will potentially alter the mineralogical composition due to the loss of $\mathrm{Fe}$ followed by $\mathrm{Si}$ and $\mathrm{Mg}$. In contrast, the refractory elements such as $\mathrm{Ca}$ and $\mathrm{Al}$ do not evaporate significantly even after $50 \%$ ablation, at which point $\mathrm{Si}$ evaporation causes a substantial increase in the $\mathrm{Ca} / \mathrm{Si}$ ratio (Figure 10(c)). The $\mathrm{Al} / \mathrm{Si}$ ratio behaves in a similar way (Figure 10(d)). The slow vaporization of $\mathrm{Ca}$ and $\mathrm{Al}$ can be useful for identifying the precursors from $\mathrm{Ca} / \mathrm{Si}$ and $\mathrm{Al} / \mathrm{Si}$ ratios. The disadvantage is the difficulty involved in considering the chemical composition of the particle that does not represent the bulk mineralogical of the precursors. Small fragments of dust generated by disruption during asteroidal collisions may be of an individual mineral or group of minerals and far from the bulk mineralogical composition of the parent bodies.

Various methods to determine the mass accretion of extraterrestrial particles has provided a wide range of estimates

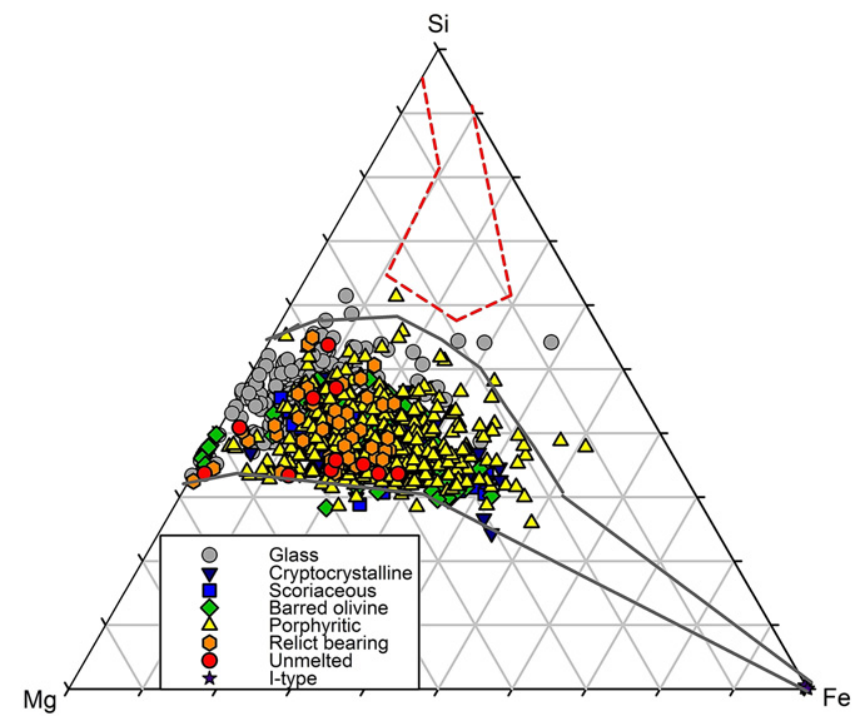

Figure 5. Ternary diagram representing $\mathrm{Mg}-\mathrm{Si}-\mathrm{Fe}$ (atoms) of different types (unmelted: 11 , relict-bearing: 42 , scoriaceous: 57 , porphyritic: 355 , cryptocrystalline: 119, barred olivine: 137 , glass: 371 , I-type: 18) of micrometeorites (total: 1110) collected from the South Pole Water Well (SPWW). The elemental ranges of micrometeorites and terrestrial particles suggested by Suavet et al. (2009) are indicated by the dark gray line and dotted red line, respectively. 


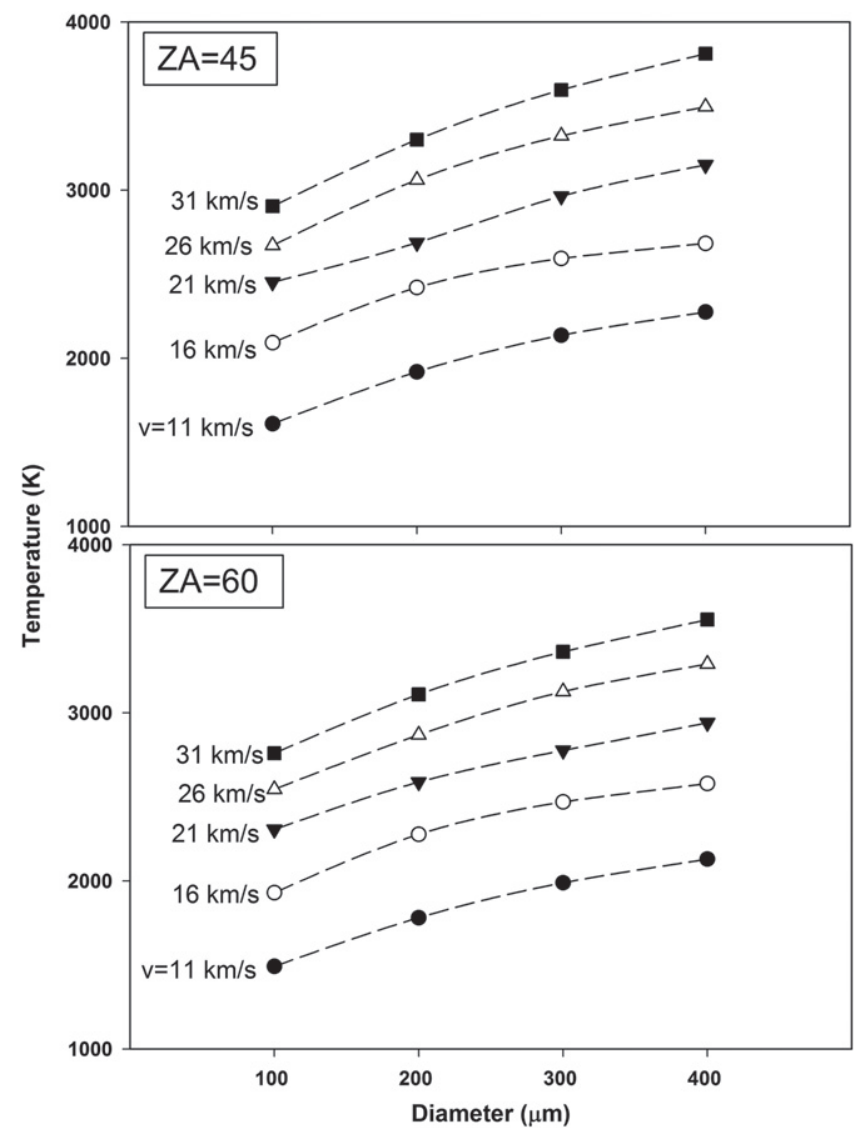

Figure 6. Distribution of temperature for different sizes of entry particles over a range of entry velocities from $\sim 11$ to $31 \mathrm{~km} \mathrm{~s}^{-1}$ for $\mathrm{ZA}=45^{\circ}$ and $60^{\circ}$. It can be seen that the temperature exceeds $2000 \mathrm{~K}$, even for a velocity of only $16 \mathrm{~km} \mathrm{~s}^{-1}$ and a diameter of a few hundred $\mu \mathrm{m}$.

(Plane 2012). The analysis of micro-impact craters on the space-facing side of the Long duration exposure facility (LDEF) satellite at an altitude of $350-480 \mathrm{~km}$ constrains the total accreted mass to be $30,000 \mathrm{t} \mathrm{yr}^{-1}$ with a large uncertainty of $\pm 20,000 \mathrm{t} \mathrm{yr}^{-1}$; however, this estimate requires an assumed velocity distribution of the particles (Love \& Brownlee 1993; Taylor et al. 1998). Os isotopes studies in marine sediments have indicated an accretion rate of $30,000 \pm 15,000$ tons $\mathrm{yr}^{-1}$ which is similar to that of the LDEF satellite estimate (PeuckerEhrenbrink \& Ravizza 2000). The accumulation of Ir, Pt, and super-paramagnetic Fe particles in polar ice cores also imply a large dust flux of at least 36,000 $\mathrm{yr}^{-1}$ (Gabrielli et al. 2004; Lanci et al. 2007). In contrast, the sampling of cosmic spherules from the SPWW gave an estimate of $2700 \pm 1400 \mathrm{t} \mathrm{yr}^{-1}$ (Taylor et al. 1998). The accretion rate of micrometeorites in blue ice was estimated to be $16,000 \pm 9000 \mathrm{tyr}^{-1}$, based on the collective analyses of handpicked particles and noble gas measurements done of the residual particles (Yada et al. 2004). The Greenland ice micrometeorite collection yields an estimate of $\sim 4000 \mathrm{t} \mathrm{yr}^{-1}$ (Maurette et al. 1987). The mass accretion rate estimated by counting cosmic spherules in deep sea sediments yielded a low estimate, as most of the fragile particles seem to get destroyed in the harsh environment (Prasad et al. 2013). Each of these estimation techniques depends on various assumptions and is then scaled up to provide the global input (Plane 2012). In any case, a significant fraction of the meteoroid flux entering the atmosphere ablates. The resulting metal vapours then oxidize and polymerize to form meteoric smoke particles (Plane et al. 2015), which is the major form of extraterrestrial material sampled in ice cores. For meteoroids with $\mathrm{ZA}=0^{\circ}-50^{\circ}$ and velocity $>16 \mathrm{~km} \mathrm{~s}^{-1}$, at least $70 \%$ of the particle mass is vaporized during entry. However, for an entry velocity $<21 \mathrm{~km} \mathrm{~s}^{-1}$ and $\mathrm{ZA}=50^{\circ}-70^{\circ}$, a particle will melt and form a cosmic spherule (such as porphyritic, barred, cryptocrystalline, glass). $\mathrm{ZA}=70^{\circ}-80^{\circ}$ is the zone where relict-grainbearing, scoriaceous spherules are partially heated and transported to the Earth's surface. As discussed earlier, unmelted micrometeorites have a very narrow window of $\mathrm{ZA}=80^{\circ}-90^{\circ}$ for velocity $\sim 16-21 \mathrm{~km} \mathrm{~s}^{-1}$, or $60^{\circ}-90^{\circ}$ for $\sim 11 \mathrm{~km} \mathrm{~s}^{-1}$.

\subsection{Micrometeorites and Their Likely Precursors}

The mineralogy of the micrometeorites is important for gaining information on the precursors from which they originated. CABMOD is useful to some extent for extrapolating from the micrometeorite back to the original mass and the nature of the meteoroid from which it formed. As shown in the ternary diagram (Figure 5), the micrometeorites in the present study fall within the limit of the extraterrestrial line, similar to those seen in other studies of Antarctic micrometeorite collections obtained either by melting ice or traps (Taylor et al. 2000; Rochette et al. 2008). The diffusion and evaporation rate of elemental $\mathrm{Fe}$ is much faster than that of $\mathrm{Mg}$ (Hashimoto 1983), which explains the occurrence of magnetite rims formed on micrometeorites during atmospheric entry. A thin Fe-rich rim is common even on unmelted particles or single minerals, suggesting that Fe fractionating in particles takes places even at relatively low temperatures. The spread in the $\mathrm{Fe} / \mathrm{Si}$ ratio in Figure 4(b) suggests that the process of diffusion or evaporation of Fe leads to the rapid depletion of $\mathrm{Fe} / \mathrm{Si}$, since there are a comparatively small number of micrometeorites near the CI value. An additional reason may be because of a large precursor that is dominated by chondrules that have low $\mathrm{Fe} / \mathrm{Si}$ values.

The $\mathrm{Mg} / \mathrm{Si}$ values are largely close to the $\mathrm{CI}$ chondrite value $(\sim 0.8-1.0)$, within the analytical error involved in estimating the bulk chemical composition of the micrometeorites. The number of micrometeorites studied here makes them appropriate for statistical interpretation. Nearly $65 \%$ of the micrometeorites from the present study have $\mathrm{Mg} / \mathrm{Si}$ values ranging from 0.8 to 1.0 , irrespective of the texture or type. CABMOD suggests that the range will have $\leqslant 20 \%$ of ablation for an entry velocity less than $16 \mathrm{~km} \mathrm{~s}^{-1}$ and ZA greater than $45^{\circ}$ marked as region I in Figure 11. For other lower velocities and similar $\mathrm{ZA}$, the ablation is much less than $20 \%$ and close to CI values and fall in region I. On the other hand, $20 \%$ of micrometeorites have bulk $\mathrm{Mg} / \mathrm{Si}$ in the range of 1.0-1.4 have ablation from $20 \%-60 \%$ suggesting large alteration during the entry (marked as region II in Figure 11). Above this range the ablation is very high with large-scale vaporization of $\mathrm{Fe}$ and $\mathrm{Si}$, and any particle that has large dimension may not be able to retrievable as a micrometeorite on the Earth's surface (marked as region III in Figure 11). For velocity $11 \mathrm{~km} \mathrm{~s}^{-1}$, the ablation is less than $20 \%$ and will lie in region I. However, $\sim 15 \%$ of particles that do not fall in these three regions are those with bulk $\mathrm{Mg} / \mathrm{Si}$ values that range between $\sim 0.6$ and 0.8 . It should be noted that the $\mathrm{Mg} / \mathrm{Si}$ ratio becomes enriched during heating due to $\mathrm{Si}$ evaporation which is much faster than $\mathrm{Mg}$. $\mathrm{A} \mathrm{Mg} / \mathrm{Si}$ ratio between $\sim 0.6$ and 0.8 therefore suggests a different precursor 
$\mathrm{v}=11 \mathrm{~km} / \mathrm{s}$

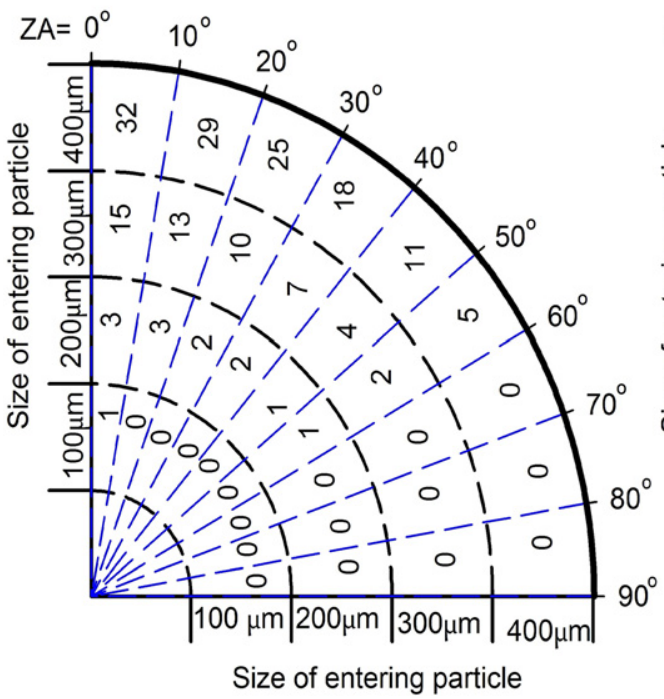

$\mathrm{v}=16 \mathrm{~km} / \mathrm{s}$

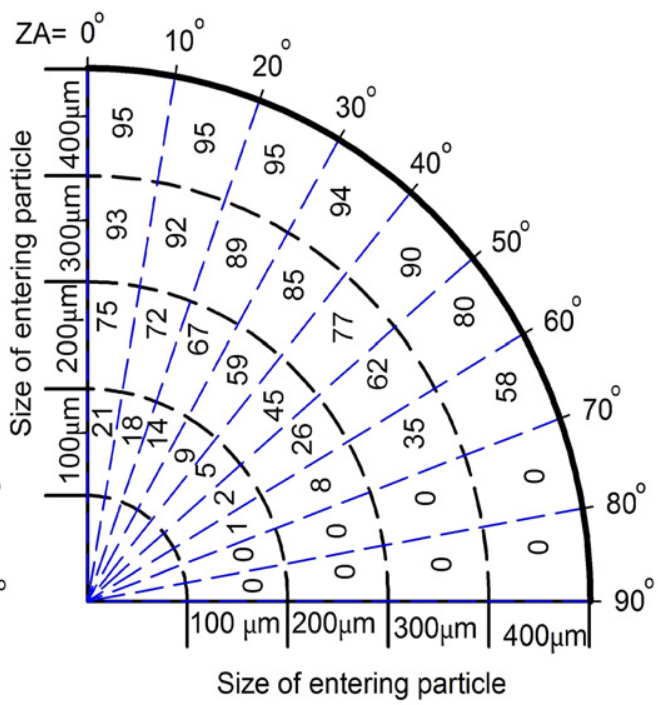

Figure 7. Percentage ablation for different particle sizes and ZAs at entry velocities of 11 and $16 \mathrm{~km} \mathrm{~s}^{-1}$. Note that unmelted particles have a narrow zone of ZA at $16 \mathrm{~km} \mathrm{~s}^{-1}$, which broadens at $11 \mathrm{~km} \mathrm{~s}^{-1}$. The number indicated is the percentage ablation (e.g., ablation is $95 \%$ for $\mathrm{ZA}=0^{\circ}$, velocity $=16 \mathrm{~km} \mathrm{~s}{ }^{-1}$, and size $=400 \mu \mathrm{m}$.

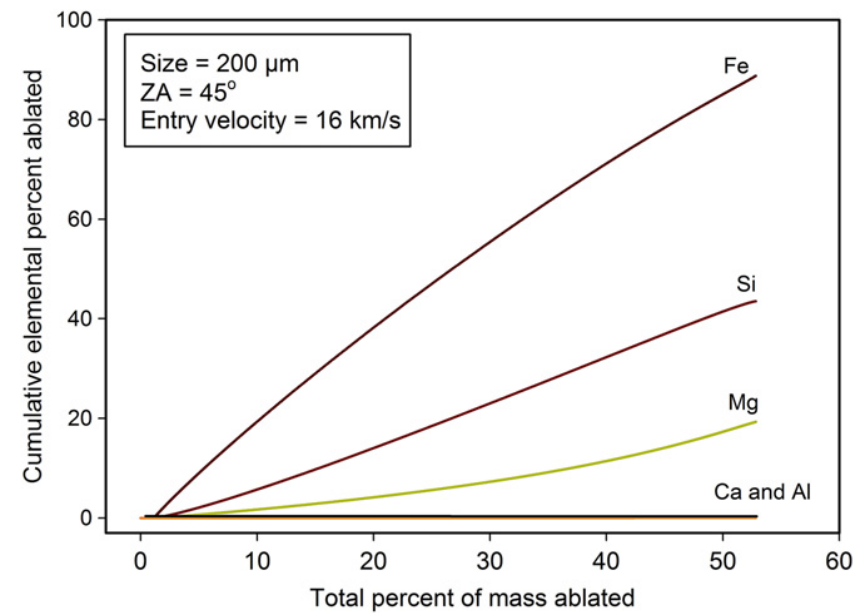

Figure 8. Contribution of individual elements to the percentage mass ablated. $\mathrm{Fe}$ ablates more rapidly than $\mathrm{Si}$ and $\mathrm{Mg}$, thereby contributing more to the total mass ablated. The contribution from refractory elements $\mathrm{Ca}$ and $\mathrm{Al}$ is very low.

from carbonaceous chondrites, such as ordinary chondrites that have $\mathrm{Mg} / \mathrm{Si}$ values of $\sim 0.8, \mathrm{EH} \sim 0.6$ and $\mathrm{EL} \sim 0.7$ (Lodders \& Fegley 1998). Thus, it appears that $\sim 15 \%$ of the total particle that survive entry have a provenance to ordinary or enstatite chondrites, while $\sim 85 \%$ are related to carbonaceous chondrites. Among all global collections of cosmic dust (Taylor et al. 2000, 2007a; Prasad et al. 2013), it is seen that a majority of the particles are sourced either from CI or CM chondrites, which can be distinguished from ordinary chondrites (Brownlee et al. 1997). Engrand \& Maurette (1998) suggested that up to $99 \%$ of the particulate flux of cosmic matter is dominated by either carbonaceous or cometary bodies, which is especially true for unmelted particles. The CI and the $\mathrm{CM}$ chondrites are more porous and hydrated and fragment easily during asteroidal collisions and produce greater quantities of dust-sized materials (Tomeoka et al. 2003) that stream into the inner solar system. The anhydrous meteorites (ordinary chondrites and others) have greater tensile strengths

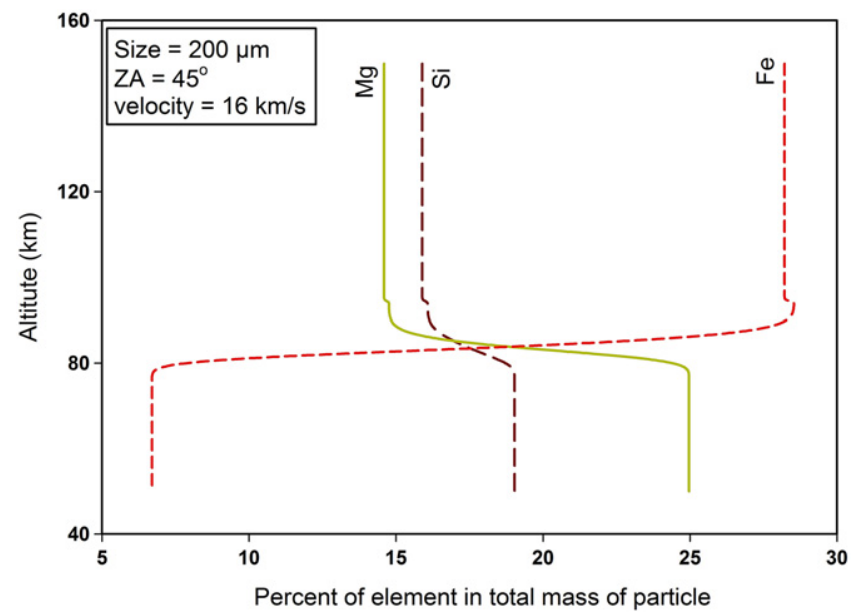

Figure 9. Change in elemental percent vs. altitude. At $80 \mathrm{~km}$ the ablation of a $200 \mu \mathrm{m}$ particle at ZA $45^{\circ}$ and entry velocity $16 \mathrm{~km} \mathrm{~s}^{-1}$ is fast; the resulting loss of Fe leads to an increase in the bulk $\mathrm{Mg}$ and $\mathrm{Si}$ composition of the particle.

and do not break down that easily into the smallest particles during comminution in the asteroid belt, therefore, their presence is not dominant among micrometeorites. On the basis of their elemental ratios and textures, the micrometeorites analysed in the present investigation also suggest a dominant contribution from carbonaceous chondrites.

\subsection{Precursors for Refractory Minerals}

The spinels are refractory minerals with melting temperatures above $2000 \mathrm{~K}$. In the present study only four micrometeorites contain spinels, which are occasionally found in the CAIs of carbonaceous chondrites. The oxygen isotope composition of the spinels in the Antarctic micrometeorites shows they are ${ }^{16} \mathrm{O}$-rich, similar to those found in CAIs, which suggests refractory inclusion (Taylor et al. 2012). P219 is nearly pure anorthitic in composition $\left(\mathrm{An}_{90-94}\right)$, with few chromite grains enclosed. These types of anorthitic-rich spherules could have originated from the CAIs of $\mathrm{CV}, \mathrm{CO}$, 

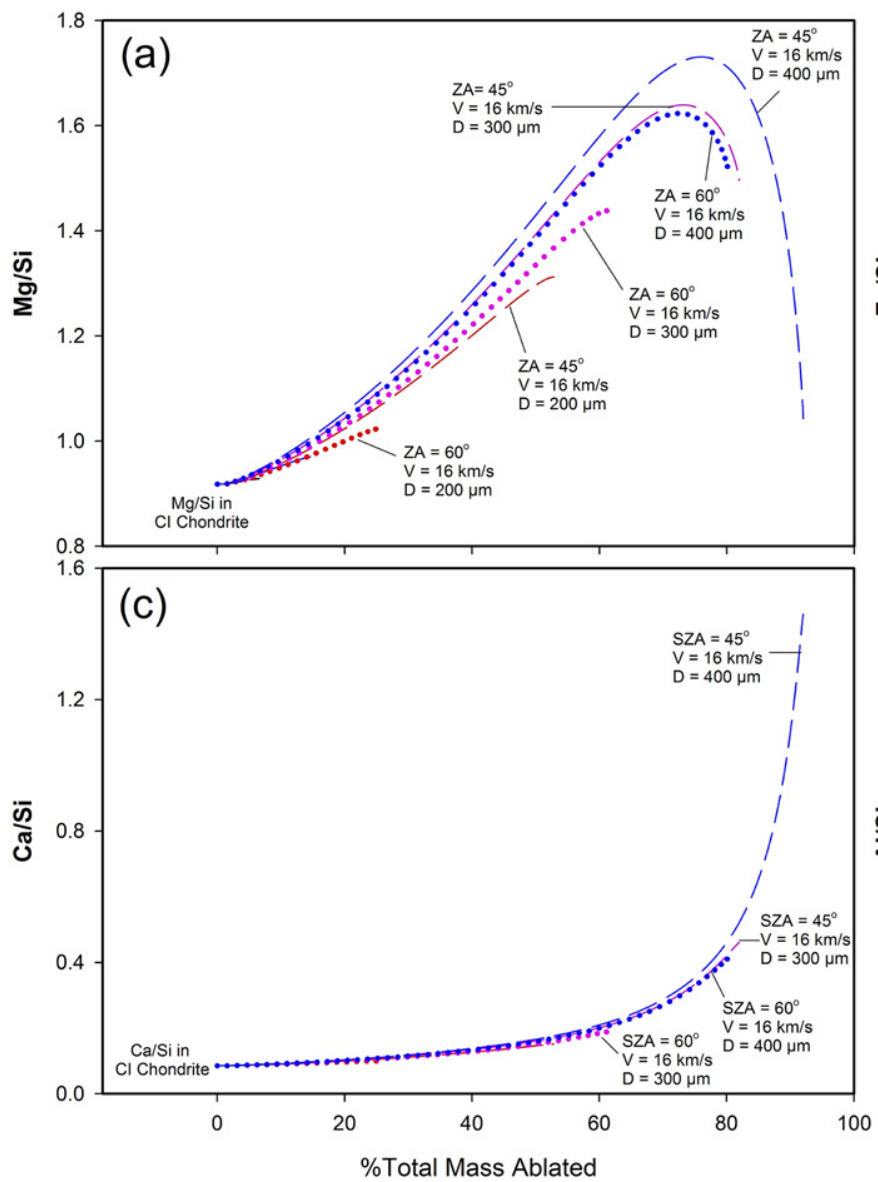
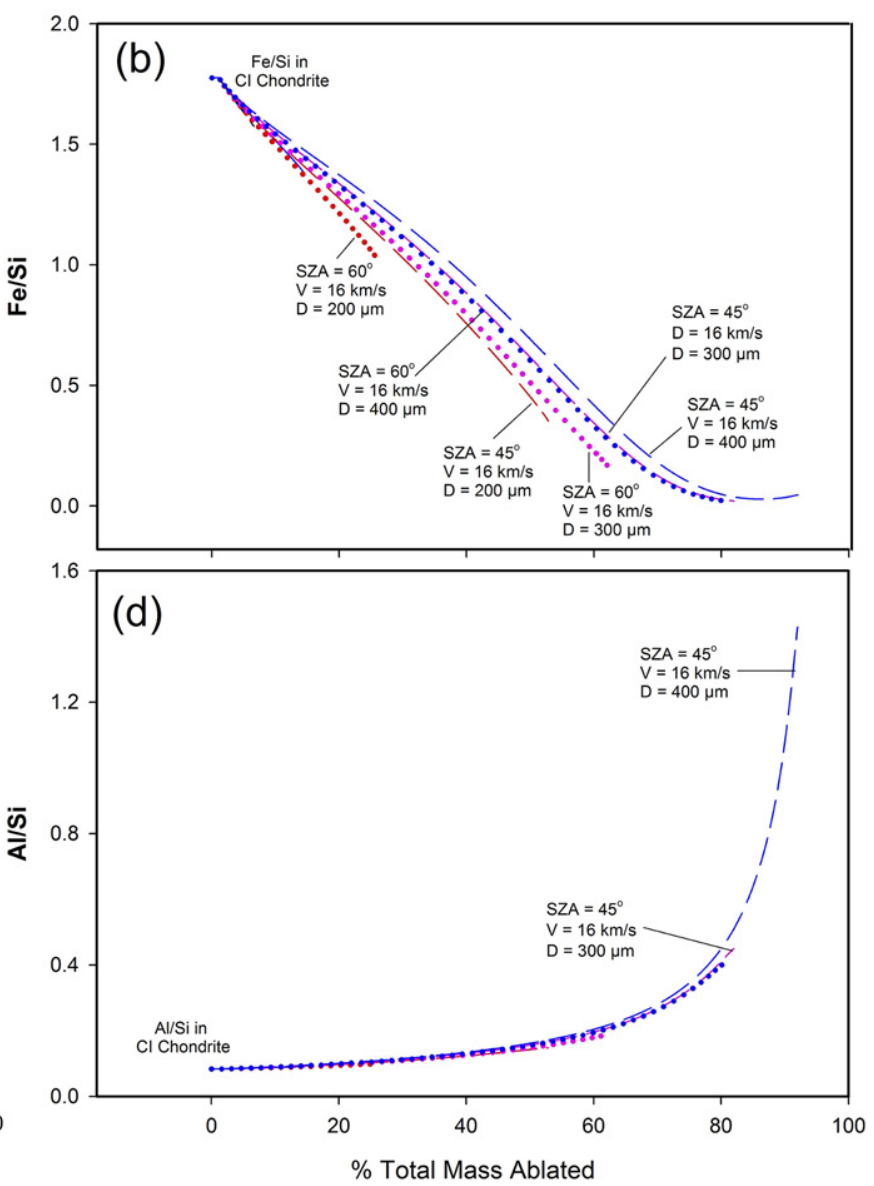

Figure 10. Change in elemental ratio with respect to the percent of mass ablated for particles of various diameters, $\mathrm{ZAs}$, and entry velocities: (a) $\mathrm{Mg} / \mathrm{Si}$, (b) $\mathrm{Fe} / \mathrm{Si}$, (c) $\mathrm{Ca} / \mathrm{Si}$, and (d) $\mathrm{Al} / \mathrm{Si}$.

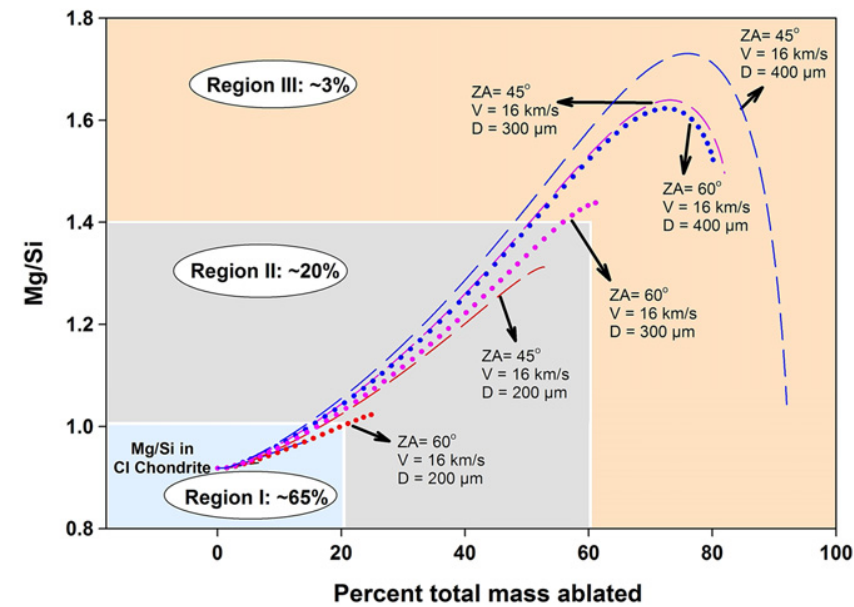

Figure 11. Variation of the $\mathrm{Mg} / \mathrm{Si}$ ratio with percent of mass ablated for different $\mathrm{ZA}$ at velocities $=11$ and $16 \mathrm{~km} \mathrm{~s}^{-1}$. The variation $\mathrm{Mg} / \mathrm{Si}$ in the 0.8-1.0 range, combined with the histogram plot of Figure 4, suggests that $\sim 65 \%$ of the particles undergo $\sim 20 \%$ ablation (region I). $\mathrm{Mg} / \mathrm{Si} \sim 1.0-1.4$ suggests that $\sim 20 \%$ of particles undergo $20 \%-60 \%$ ablation (region II). Only $3 \%$ of particles that undergo more than $60 \%$ ablation survive atmospheric entry (region III).

CH, and CR chondrites (Krot \& Keil 2002). The number of micrometeorites with a CAI component is less than $0.5 \%$, which is far from the $\mathrm{CM}, \mathrm{CO}, \mathrm{CV}$, and $\mathrm{CK}$ chondrites which have $\sim 1.2 \%, 1.0 \%$, and $3.0 \%$ modal abundances (Hezel et al. 2008). One of the primary reasons for a poor contribution from refractory minerals toward the flux of micrometeorites is the very fluffy nature: the loosely packed assemblage with a large void space easily disintegrates during collisions either in the asteroidal belt or during atmospheric entry (Lal \& Jull 2002). Only fragments that have similar mineral assemblages have a greater chance of survival.

\section{CONCLUSIONS}

A CABMOD has been used to evaluate the effect of meteoroid size, velocity, and ZA on the degree of ablation and chemical variation of particles entering the atmosphere. We describe the analyses of 1133 micrometeorites collected from the SPWW. We predict, based on the measured $\mathrm{Mg} / \mathrm{Si}$ ratios of the micrometeorites and the CABMOD analysis, that $\sim 15 \%$ of recovered samples are either ordinary or enstatite chondrites as precursors, while the rest have a carbonaceous chondritic origin. The unmelted micrometeorites that contribute half of the total flux that reaches Earth's surface have a very narrow ZA of $60^{\circ}-90^{\circ}$ and $80^{\circ}-90^{\circ}$ for entry velocity $\sim 11$ and $>11-21 \mathrm{~km} \mathrm{~s}^{-1}$. In spite of the fact that the micrometeorites recovered on the surface have often undergone large-scale alteration during entry, a significant number of micrometeorites $(\sim 65 \%)$ have $\mathrm{Mg} / \mathrm{Si}$ ratios $\sim 0.8-1.0$, suggesting modest ablation of less than $20 \%$, while another $20 \%$ of the particles have undergone $20 \%-60 \%$ ablation. This quantification of ablation is important for estimating the micrometeorite precursor sizes and flux. 
This work is supported by the CSIR XII Plan funded Project GEOSINKS and the PLANEX project, Physical Research Laboratory, Ahmedabad (N.G.R. and M.S.P.). This is NIO's contribution No. 5823. The work at the University of Leeds is supported by the European Research Council (project number 291332-CODITA).

\section{REFERENCES}

Berlin, J. 2009, PhD thesis, Univ. New Mexico

Blanchard, M. B., Brownlee, D. E., Bunch, T. E., Hodge, P. W., \& Kyte, F. T. 1980, EPSL, 46, 178

Brownlee, D. E. 2001, in Acretion of Extraterrestrial Matter Throughout Earth's History, ed. B. Peucker-Ehrenbrink \& B. Schmitz (New York: Kluwer/Plenum)

Brownlee, D. E., Bates, B., \& Schramm, L. 1997, M\&PS, 32, 157

Dermott, S. F., Jayaraman, S., Xu, Y. L., Grogan, K., \& Gustafson, B. A. S. 1996, in AIP Conf. Proc. 348, The Origin and Dynamics of the Interplanetary Dust Cloud (Melville, NY: AIP), 25

Dermott, S. F., Jayaraman, S., Xu, Y. L., Gustafson, B. A. S., \& Liou, J. C. 1994, Natur, 369, 719

Engrand, C., \& Maurette, M. 1998, M\&PS, 33, 565

Flynn, G. J. 1989a, LPSC, 19, 673

Flynn, G. J. 1989b, Icar, 77, 287

Fraundorf, P. 1980, GRL, 7, 765

Gabrielli, P., Barbante, C., Plane, J. M. C., et al. 2004, Natur, 432, 1011

Genge, M. J., Engrand, C., Gounelle, M., \& Taylor, S. 2008, M\&PS, 43, 497

Gounelle, M., Chaussidon, M., Morbidelli, A., et al. 2009, PNAS, 106, 6904

Hashimoto, A. 1983, GeocJ, 17, 111

Hezel, D. C., Russell, S. S., Ross, A. J., \& Kearsley, A. T. 2008, M\&PS, 43, 1879

Kortenkamp, S. J., \& Dermott, S. F. 1998, Icar, 135, 469

Kortenkamp, S. J., Dermott, S. F., Fogle, D., \& Grogan, K. 2001, in Acretion of Extraterrestrial Matter Throughout Earth's History, ed. B. Peucker-Ehrenbrink \& B. Schmitz (New York: Kluwer/Plenum)

Krot, A. N., \& keil, K. 2002, M\&PS, 37, 91

Lal, D., \& Jull, A. J. T. 2002, ApJ, 576, 1090

Lanci, L., Kent, D. V., \& Biscaye, P. E. 2007, GRL, 34, L10803

Lodders, K., \& Fegley, B., Jr. 1998, The Planetary Scientist's Companion (New York: Oxford Univ. Press)
Love, S. G., \& Brownlee, D. E. 1991, Icar, 89, 26

Love, S. G., \& Brownlee, D. E. 1993, Sci, 262, 550

Love, S. G., Joswiak, D. J., \& Brownlee, D. E. 1994, Icar, 111, 227

Mason, B. 1971, Handbook of Elemental Abundances of the Elements in Meteorites (Newark, USA: Gordon and Breach)

Maurette, M., Jéhanno, C., Robin, E., \& Hammer, C. 1987, Natur, 328, 699

Nesvorný, D., Janches, D., Vokrouhlický, D., et al. 2011, ApJ, 743, 129

Nesvorný, D., Jenniskens, P., Levison, H. F., et al. 2010, ApJ, 713, 816

Peucker-Ehrenbrink, B., \& Ravizza, G. 2000, GCA, 64, 1965

Plane, J. M. C. 2012, Chem. Soc. Rev., 41, 6507

Plane, J. M. C., Feng, W., \& Dawkins, E. C. M. 2015, ChRv, 115, 4497

Pouchou, J. L., \& Pichoir, F. 1991, in Electron Probe Quantification, ed. K. F. J. Heinrich \& D. E. Newbury (New York: Plenum)

Prasad, M. S., Rudraswami, N. G., \& Panda, D. K. 2013, JGR, 118, 2381

Reach, W. T., Franz, B. A., \& Weiland, J. L. 1997, Icar, 127, 461

Rochette, P., Folco, L., Suavet, C., et al. 2008, PNAS, 105, 18206

Rudraswami, N. G., Prasad, S. M., Plane, J. M. C., et al. 2014, GCA, 131,247

Rudraswami, N. G., Shyam Prasad, M., Babu, E. V. S. S. K., et al. 2012, GCA, 99, 110

Rudraswami, N. G., Shyam Prasad, M., Nagashima, K., \& Jones, R. H. 2015, GCA, 164, 53

Schaefer, L., \& Fegley, B. 2005, EMP, 95, 413

Sears, D. W., \& Dodd, R. T. 1988, in Meteorites and the Early Solar System, ed. J. F. Kerridge \& M. S. Matthews (Tucson, AZ: Univ. Arizona Press)

Suavet, C., Gattacceca, J., Rochette, P., et al. 2009, JGR, 114, B04102

Taylor, S., Alexander, C. M. O’D., \& Wengert, S. 2008, LPSC, 39, 1628

Taylor, S., \& Brownlee, D. E. 1991, Metic, 26, 203

Taylor, S., Herzog, G. F., \& Delaney, J. S. 2007a, M\&PS, 42, 223

Taylor, S., Lever, J. H., \& Harvey, R. P. 1998, Natur, 392, 899

Taylor, S., Lever, J. H., \& Harvey, R. P. 2000, M\&PS, 35, 651

Taylor, S., Matrajt, G., \& Guan, Y. 2012, M\&PS, 47, 550

Taylor, S., Matrajt, G., Lever, J. H., Joswiak, D. J., \& Brownlee, D. E. 2007b, in Workshop on Dust in Planetary Systems, ed. H. Kruger \& A. Graps (ESA SP-643; Paris: ESA), 26

Tomeoka, K., Kiriyama, K., Nakamura, K., Yamahana, Y., \& Sekine, T. 2003, Natur, 423, 60

Vondrak, T., Plane, J. M. C., Broadley, S., \& Janches, D. 2008, ACP, 8,7015

Yada, T., Nakamura, T., Noguchi, T., et al. 2005, GCA, 69, 5789

Yada, T., Nakamura, T., Takaoka, N., et al. 2004, EPS, 56, 67 